\title{
Ultrasonic properties of composites (polymer-fibre glass)
}

\author{
N A ABD EL-MALAK \\ National Institute for Standards, Egypt \\ MS received 15 October 1996; revised 9 June 1997
}

\begin{abstract}
Majority of composite materials used in industry consist of polyester as a matrix and fibre glass as a reinforcement material. Five samples with different fibre glass contents were studied ultrasonically, using pulse echo technique to determine their ultrasonic properties. Results showed that the ultrasonic velocity, elastic moduli and activation energies associated with their relaxation process increase with the increase of the fibre glass content. The study showed the utility of using these inexpensive materials as sound absorbing devices and as backing materials in the manufacture of ultrasonic transducers.
\end{abstract}

Keywords. Fibre glass; composite.

\section{Introduction}

Composites are made, in general, from two or more materials combined on a microscopic scale to form a material of required properties. The first material forming the composite is the matrix, which gives the bulk form of the composite. It encloses the other constituents and essentially protects them chemically and thermally. The second material is the reinforcement, which plays an important role in the mechanical properties and behaviour of the composite. Matrix and reinforcement are bonded together and create a phase called the interphase. This interphase has an important effect on the mechanical properties of the composite, especially in highly reinforced composites with large interphase area.

The main advantage (Younis 1995) of composites is that they usually exhibit the best qualities of their constituents compared with the sum of the properties of each constituent taken separately.

There has been a rapid growth in the use of fibre-reinforced-materials, which has been achieved mainly by the replacement of traditional materials, primarily metals.

On the basis of strength and stiffness alone, fibre-reinforced composite materials do not have a clear advantage, particularly when it is noted that their elongation to fracture is much lower than that of a metal with comparable strength.

Hull (1981) showed that the large nonlinear deformation evident in the stress/strain curves of short fibre-reinforced thermoplastics is due to deformation and creep of the matrix as thermoplastics can undergo large amounts of plastic flow before fracture. Sato et al (1988) carried out electron microscopic observations on the tensile side of a sample in a bending test. The fibre ends were found to separate from the matrix and this was followed by the appearance of interfacial cracks. The debonded regions of the neighbouring fibres were then joined by bands of microcracks within the matrix. It was also observed that plastic deformation occurred around the fibre ends as a result of shear stress concentration.

Gupta et al (1990) made an attempt to identify the energy absorbing mechanism in a stress/strain test by first obtaining the tensile load-elongation curves at a low-strain rate on samples cut in different directions from an extruded short-fibre-reinforced 
polypropylene sheet with good fibre alignment. The acoustic emission measurements during the tensile test and scanning electron microscopy of fracture surfaces were also undertaken to obtain an understanding of the energy-absorbing mechanisms.

The usefulness of ultrasonics for detection and characterization of flaws in a material is well known. Considerable progress has been made towards a theoretical description of the scattering process in polycrystalline materials. Many authors (Klinman et al 1980; Vary 1980; Smith and Reynolds 1982), showed that ultrasonics has proved useful for the nondestructive evaluation of materials properties such as stress, toughness, hardness etc. However, the theoretical understanding of ultrasonic propagation in such materials is usually based on the scattering properties of a single inclusion or a void. It is not known to what concentration the single-scatterer approximation remains useful and of what form are the multiple-scattering corrections required.

Kinra et al (1982) investigated the frequency dependence of the ultrasonic velocity in samples with lead inclusions in an epoxy matrix. Sayers and Smith (1982) compared their experiments with spherical lead inclusions with the predictions of the singlescattering theory of Ying and Truell (1956) and Truell et al (1969). They found that samples with $5 \mathrm{wt} . \%$ concentration of inclusion are in reasonable agreement with single-scatterer theory. However, measurements on samples with $15 \mathrm{wt} . \%$ lead showed noticeable deviations, which were interpreted as due to multiple-scattering effects.

Madhava et al (1983) reported the results of ultrasonic velocity and attenuation measurements in randomly oriented chopped coir-polyester composites, containing up to $30 \mathrm{vol} \%$ as received or alkali-treated coir fibres. These measurements were performed with a view to examine, non-destructively, the bonding between the fibre and the matrix, and also to assess the sound absorptive potential of these composites. They found that the longitudinal ultrasonic velocity decreases with the increase in fibre content for both as-received and treated fibre composites, but this decrease was clear in composites containing as-received fibres than in those containing alkali-treated coir. This behaviour was understood within the framework of theories of effective elastic moduli of randomly oriented chopped fibre composites. In the case of coir-polyester composites where the elastic moduli of coir are somewhat higher than those of the polyester matrix, the effective moduli theories indicate an increase in longitudinal velocity with increase in the fibre content. These theories assume ideal conditions: an uniform distribution of the randomly-oriented fibres in the matrix, absence of voids and a perfect interfacial bonding between the fibres and the matrix. It was found that the fibre matrix bonding is better in case of composites containing alkali-treated coir fibres than in those containing as-received fibres. For both treated and untreated fibre composites, ultrasonic attenuation increases also with the increasing fibre content.

Reger et al (1992) determined Young's and shear moduli of an unidirectional glass fibre reinforced epoxy composite, using ultrasonics and mechanical tests. A comparison between the two methods showed no significant difference in Young's moduli, but a small difference in shear moduli, that can be related to a larger scatter encountered with the three-point bend test. The author also illustrated that the ultrasonic measurements technique is a non-destructive test that is well adapted for the determination of all the stiffness coefficients of anisotropic materials.

The present work deals with the characterization of one of the most versatile polymeric material locally produced and used in many glass fibre-reinforced polyester industries. 


\section{Experimental}

\subsection{Materials}

Specimens used in this work were machined from polyester-fibre glass sheets, which were produced and provided by Egypt Fibre Company. The sheets were fabricated by the manufacturers using hand lay-up method. Fibre weight fraction was determined prior to the lay-up. A certain amount of the matrix material was then weighed and the number of fibre glass layers required to produce the composite material of specific thickness were also weighed; hence the weight fraction could be calculated. To ensure that the calculated fibre weight fraction was equal to that of the resulting composite, within acceptable limits, a suitable specimen from the fabricated composite was weighed prior to placing it in a furnace at a temperature $923^{\circ} \mathrm{K}$ for about $30 \mathrm{~min}$. As a result, the polyester was burnt and the fibre glass could be weighed to determine the fibre weight fraction.

Composition of specimens used in this study were (i) $100 \mathrm{wt} \%$ pure polyester, (ii) $72 \mathrm{wt} . \%$ polyester, $28 \mathrm{wt} . \%$ fibre glass, (iii) $70 \mathrm{wt} . \%$ polyester, $30 \mathrm{wt} . \%$ fibre glass, (iv) $60 \mathrm{wt} . \%$ polyester, $40 \mathrm{wt} . \%$ fibre glass and (v) $40 \mathrm{wt} . \%$ polyester, $60 \mathrm{wt} . \%$ fibre glass.

\subsection{Density measurements}

Densities of the composites were measured by the displacement method using toluene.

\subsection{Ultrasonic measurements}

Attenuation of longitudinal ultrasonic waves in the investigated specimens was measured using a conventional pulse echo technique. An ultrasonic flaw detector USM3 produced by Krautkrämer was used. This apparatus operates in the frequency range $0.5-12 \mathrm{MHz}$ and usually one transducer is used as a transmitter and receiver at the same time.

Attenuation coefficient of longitudinal ultrasonic waves $(\alpha)$ is calculated from (Mongy et al 1982):

$$
\alpha=\frac{20 \log \left(l_{1} / l_{2}\right)}{2 x}
$$

where $l_{1}$ and $l_{2}$ are the amplitudes displayed on CRO of two successive reflected echoes and $x$ the sample thickness. The attenuation measurements were carried out at four different frequencies: $2,4,6$, and $8 \mathrm{MHz}$, in the temperature range $250-410^{\circ} \mathrm{K}$.

A special sample holder for mounting the transducer and the sample was constructed at the National Institute of Standards workshop and was used for the purpose.

Attenuation coefficient $(\alpha)$ measurements were taken at intervals of every three degrees. The ultrasonic longitudinal velocity and shear velocity were measured using delay time between two successive echoes. 
The complex longitudinal modules $L^{*}$ of the material can be derived by the following relations (Nguyen et al 1995)

$$
\begin{aligned}
L^{*} & =L^{\prime}+L^{\prime \prime}, \\
\tan \delta & =\frac{L^{\prime \prime}}{L^{\prime}}, \\
L^{\prime} & =V_{L}^{2} \rho, \\
L^{\prime \prime} & =\frac{\alpha}{\pi f} V_{L}^{3} \rho,
\end{aligned}
$$

where $L^{\prime}, L^{\prime \prime}$ and $\tan \delta$ are the real and imaginary parts of the longitudinal modulus and the loss tangent $V_{L}, \alpha, f$ and $\rho$ are the longitudinal velocity, attenuation, frequency and density.

Considering the effective modulus of a longitudinal wave, the elastic moduli can be calculated from the equations:

$$
\begin{aligned}
& L=\rho V_{L}^{2}, \\
& G=\rho V_{\mathrm{s}}^{2}, \\
& K=L-4 / 3 G, \\
& E=(1+\sigma) \times 2 G, \\
& H=(1-2 \sigma) E / 6(1+\sigma),
\end{aligned}
$$

where $L, G, K$ and $E$ are longitudinal, shear, bulk and Young's moduli, $H$ the microhardness, $V_{\mathrm{s}}$ the shear velocity and $\sigma$ the Poisson's ratio.

\section{Results and discussion}

The results of the relation between ultrasonic velocities and fibre glass fraction of the composites under investigation are shown in figure 1 . It is evident from the figure that the velocity did not suffer from dispersion of fibre glass content (reinforcement). Both $V_{1}$ and $V_{\mathrm{s}}$ increase with the increase of fibre glass content. However, this increase is more pronounced in composites containing more than $30 \mathrm{wt} \%$ fibre glass. This behaviour can be understood within the framework of theories of effective elastic moduli of randomly-oriented composites (Chang and Weng 1979). The effective moduli theories indicate an increase in longitudinal velocity with increasing fibre content. These theories, however, assume ideal conditions such as absence of voids and perfect interfacial bond between the fibre and the matrix. The observed $V_{1}$ and $V_{\mathrm{s}}$ variations indicate that the fibre glass is uniformly distributed in the matrix.

Figure 2 shows the relation between ultrasonic attenuation and fibre glass content at 2 and $4 \mathrm{MHz}$ frequency. The results of ultrasonic attenuation show these samples to have practical value as the results (Sayers and Smith 1982) suggest that the ultrasonic attenuation is rather less sensitive to multiple scattering effect. The curves of figure 2 show that the ultrasonic attenuation $(\alpha)$ increases with the increase of fibre glass content and also $\alpha$-values are somewhat higher for samples with compositions containing more than $30 \mathrm{wt} . \%$ fibre glass. This increase in the attenuation values proves the sound 


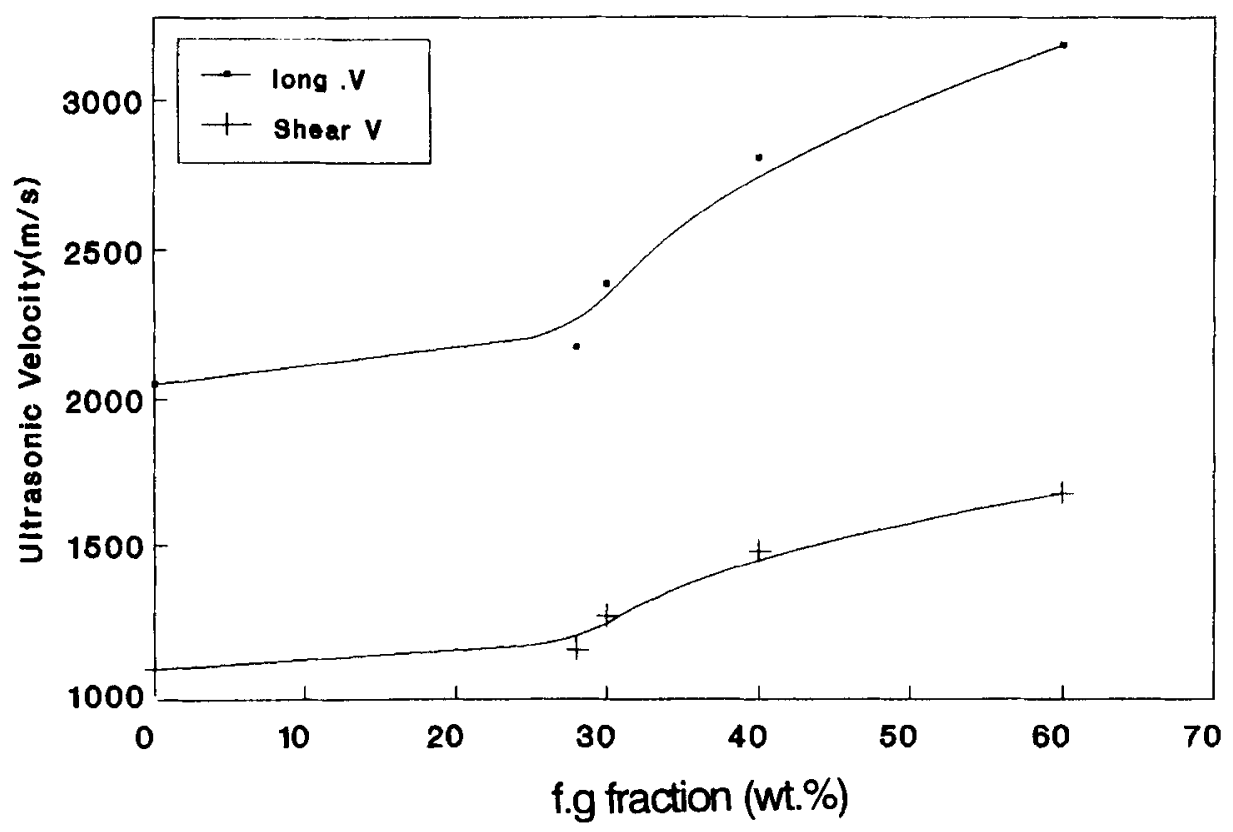

Figure 1. Relation between U.S. velocity and F.G. fraction.

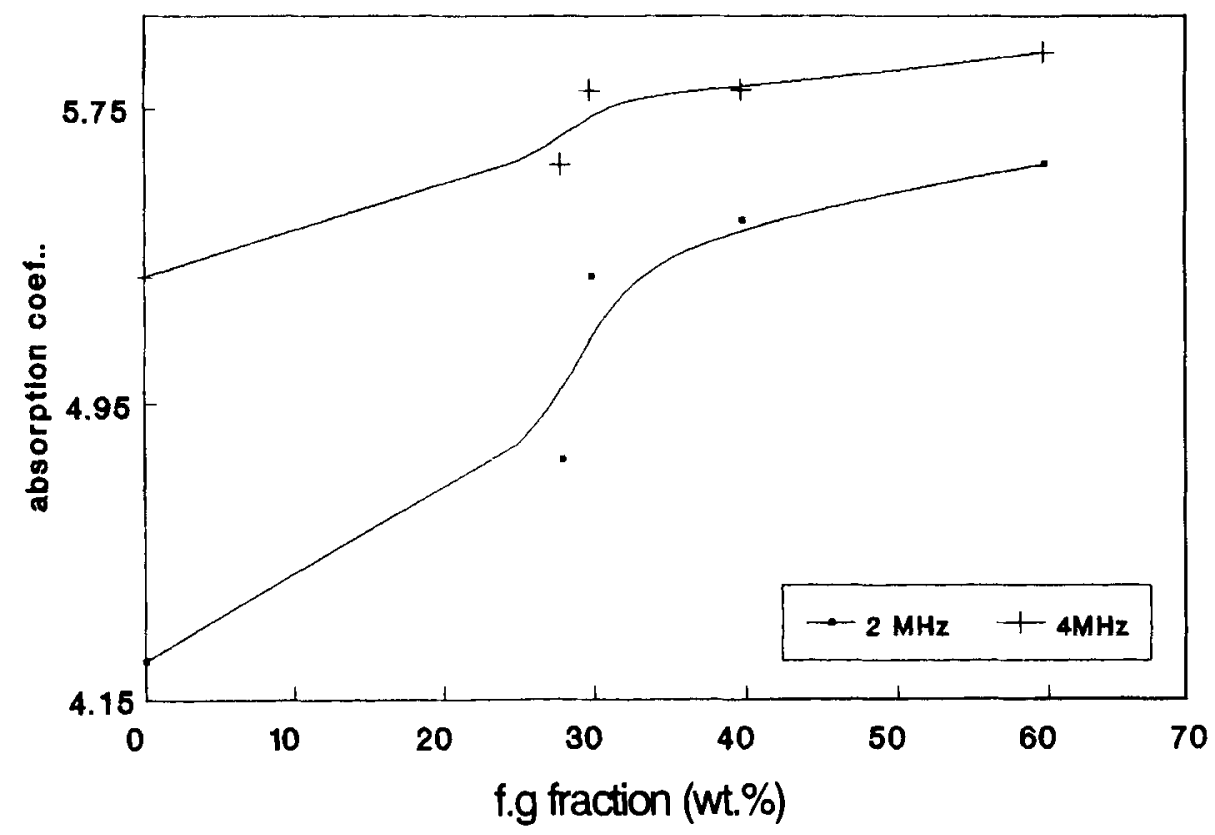

Figure 2. Relation between F.G. fraction and absorption coefficient.

absorptive potential of these inexpensive materials. These composites can thus be used in the manufacture of ultrasonic transducers where such composites can be used as backing materials. 


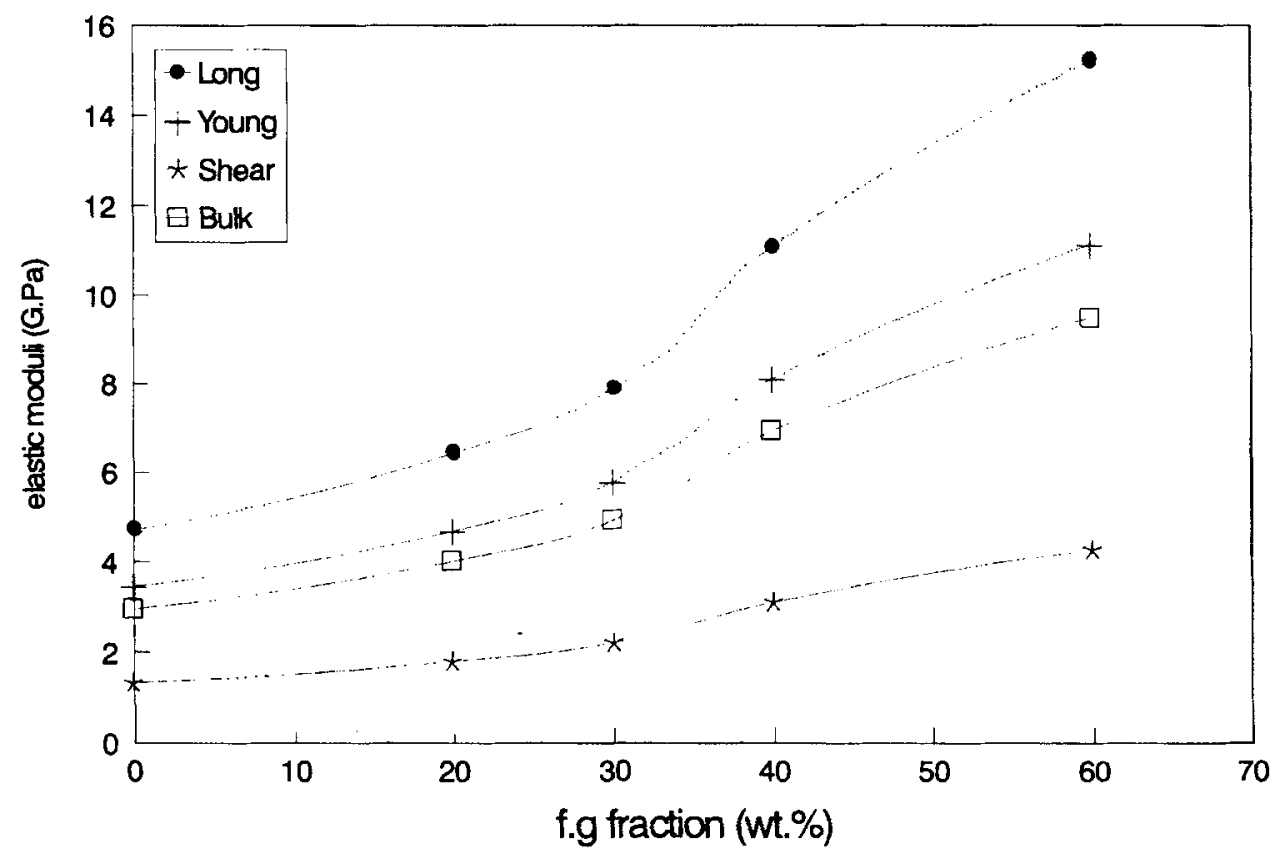

Figure 3. Relation between elastic moduli and F.G. fraction.

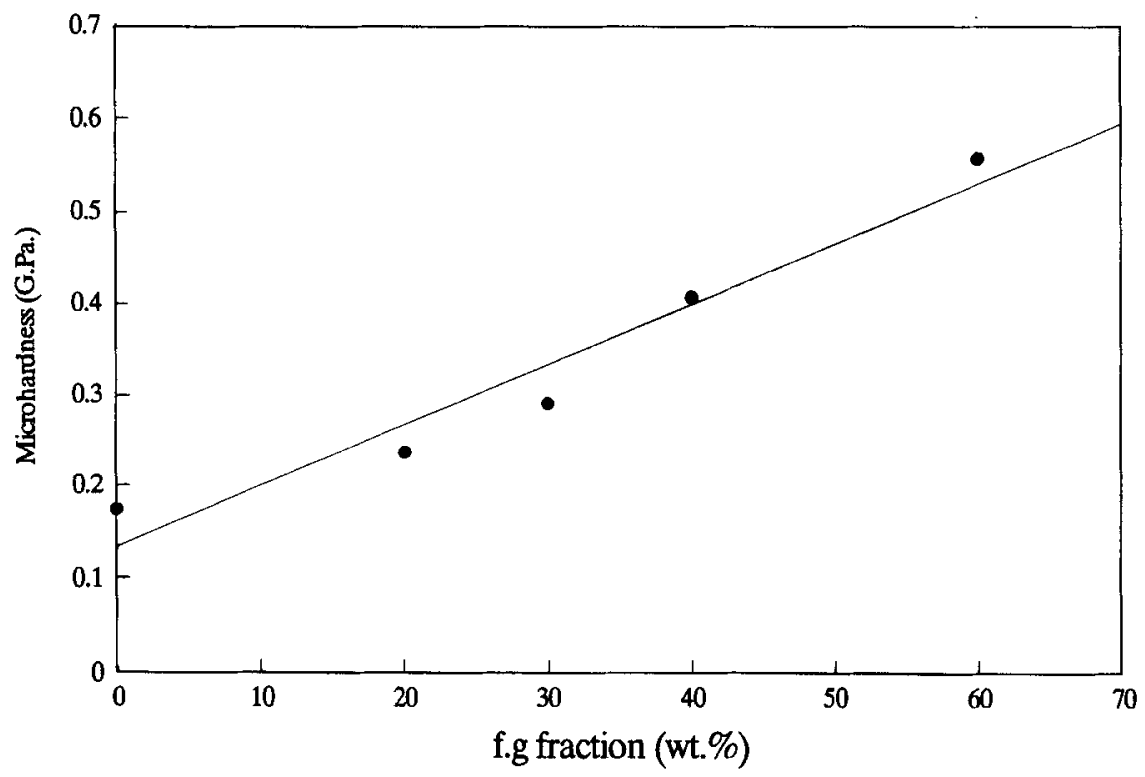

Figure 4. Relation between microhardness and F.G. fraction.

The variation of the elastic moduli values with the fibre glass content is shown in figure 3. The elastic moduli increases with the increase of fibre glass content and the increase in the elastic moduli values is more pronounced in compositions containing more than $30 \mathrm{wt} . \%$ fibre glass. The values of longitudinal elastic moduli determined ultrasonically were compared with those measured mechanically (Younis 1995) 
and good agreement was found. For example, the values for specimen having $30 \mathrm{wt} . \%$ fibre glass, as determined ultrasonically and mechanically, are 7.17 and $6.63 \mathrm{GPa}$ respectively. For specimen containing $40 \mathrm{wt} . \%$ fibre glass the values are 10.05 and $9.5 \mathrm{GPa}$. This indicates that experimental measurements carried out on the composite samples are very reliable. Figure 4 also shows that the micro hardness increases with the increase of fibre glass content, which gives the same trend as above.

Ultrasonic attenuation for polyester and different compositions $(28,30,40$ and $60 \mathrm{wt} . \% \mathrm{f.g}$ ) was measured at 2, 4, 6 and $8 \mathrm{MHz}$ frequency.

Over the whole temperature range, there is only one defined peak which shifts its position towards higher temperature with increasing frequency (Mongy et al 1982). It is observed that as the frequency increases, both the attenuation and the transition temperature increase.

Figure 5 shows the relation between the ultrasonic attenuation and temperature for polyester at 2, 4, 6 and $8 \mathrm{MHz}$ frequency. Figure 6 shows the relation between ultrasonic attenuation and temperature for different composites $(28,30,40$ and $60 \mathrm{wt} . \%$ f.g) at $2 \mathrm{MHz}$ frequency. The attenuation and transition temperature increases with increasing fibre glass fraction. Figure 7 depicts the variation of the reciprocal of transition temperature and logarithm of the applied frequency for the samples under study. From the slope of the straight lines representing this relation, the activation

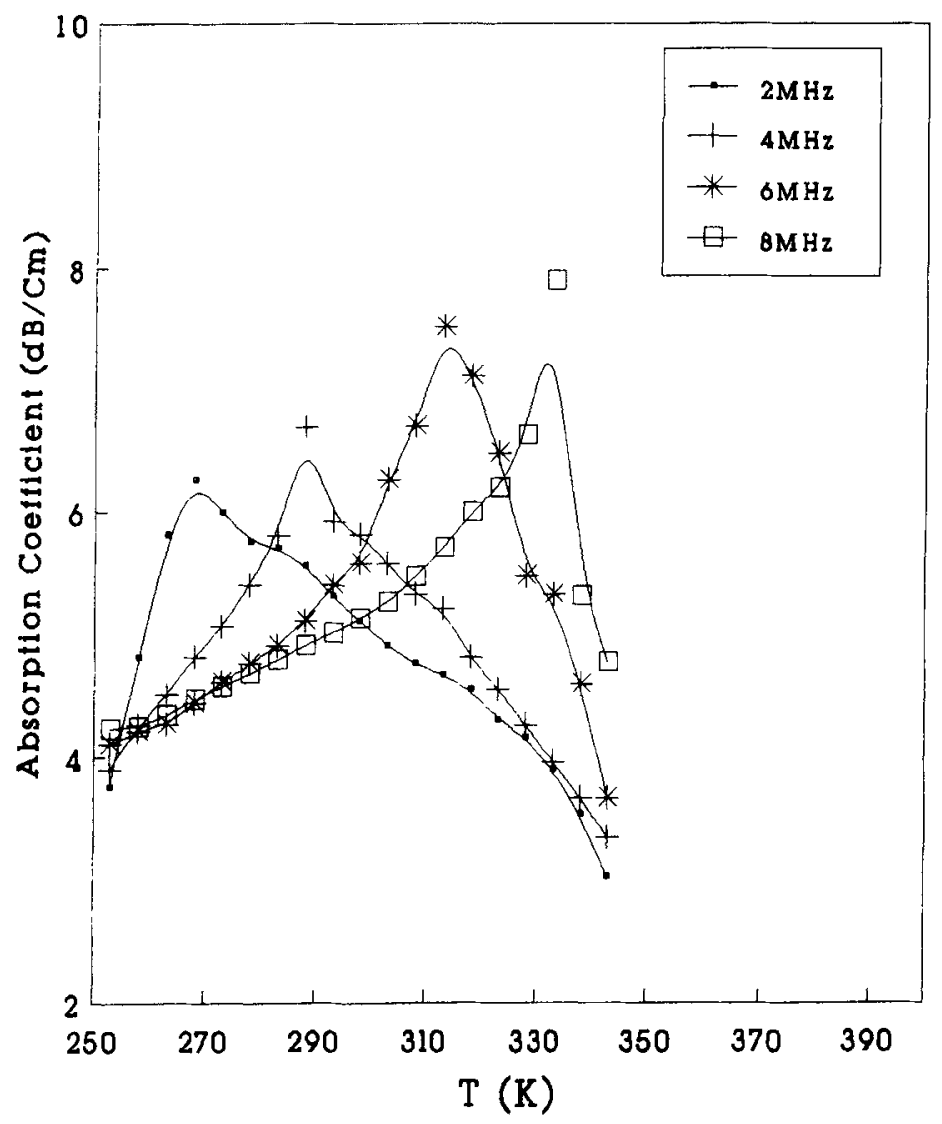

Figure 5. Absorption coefficient of polyester. 


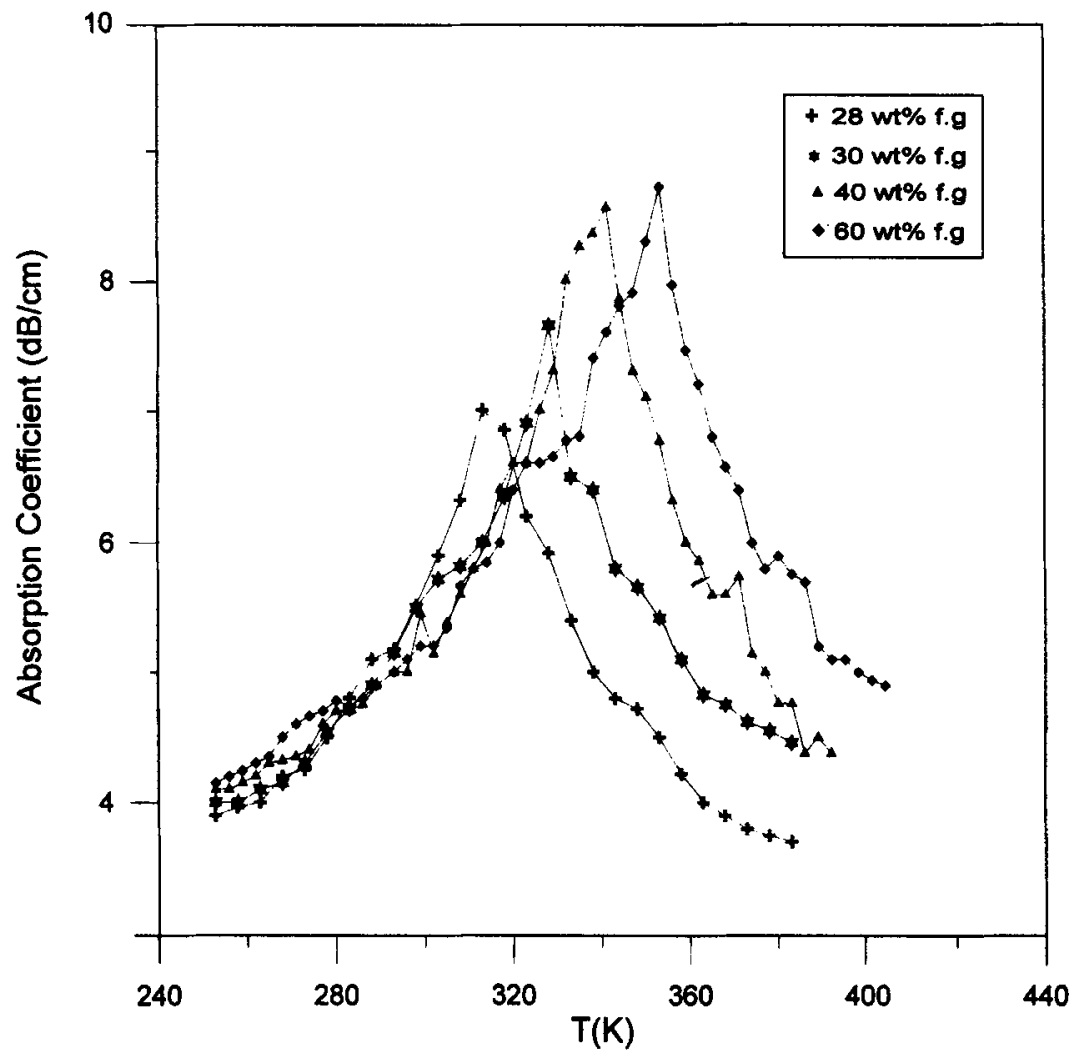

Figure 6. Absorption coefficient for composites (with $28,30,40$ and 60 wt.\% F.G. fraction) at frequency $2 \mathrm{MHz}$.

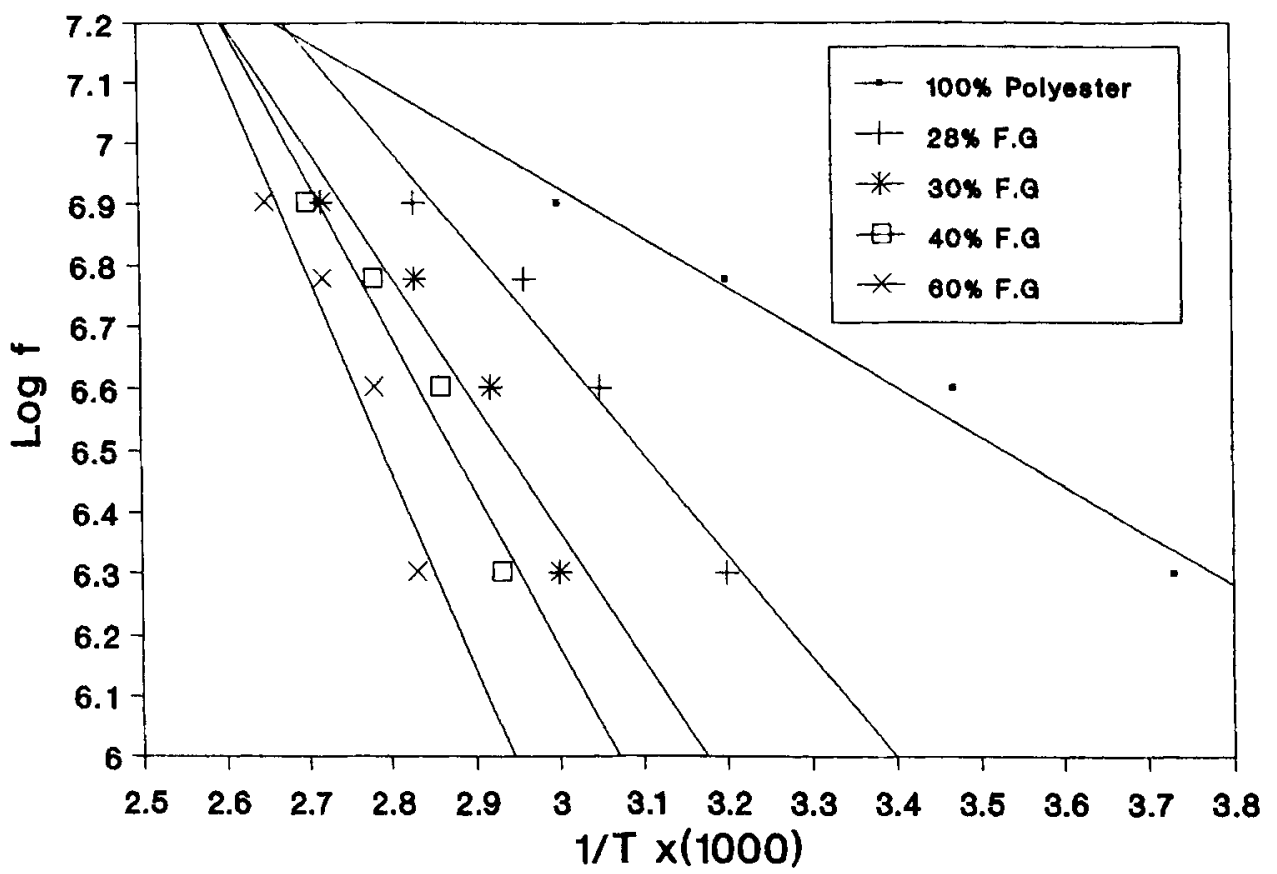

Figure 7. Relation between $\log f$ and $1 / T(\max )$. 
Table 1. Sample parameters associated with transition and activation energy.

\begin{tabular}{llccc}
\hline Sample & $\begin{array}{c}\text { Density } \\
\left(\mathrm{kg} / \mathrm{m}^{3}\right)\end{array}$ & $\begin{array}{c}\text { Peak } \\
\text { temp. }(\mathrm{K})\end{array}$ & $\begin{array}{c}\text { Relaxation } \\
\text { frequency }(\mathrm{MHz})\end{array}$ & $\begin{array}{c}\text { Activation } \\
\text { energy (Joule) }\end{array}$ \\
\hline Polyester & 1125 & 268 & $2.5 \times 10^{17}$ & $115.08 \times 10^{-22}$ \\
$28 \%$ f.g. & 1343.3 & 313 & $2.63 \times 10^{14}$ & $237.5 \times 10^{-22}$ \\
$30 \%$ f.g. & 1371 & 333 & $5.0 \times 10^{13}$ & $287.2 \times 10^{-22}$ \\
$40 \%$ f.g. & 1389 & 341 & $3.548 \times 10^{12}$ & $328.68 \times 10^{-22}$ \\
$60 \%$ f.g. & 1469 & 353 & $8.912 \times 10^{9}$ & $469.54 \times 10^{-22}$
\end{tabular}

energy, $W$ and the relaxation frequency $f_{0}$ are determined. Table 1 gives the parameters associated with the transition in these samples determined from Arrhenius equation given as,

$$
f=f_{0} e^{-W / K T_{\mathrm{m}}}
$$

where $f$ is the applied frequency, $f_{0}$ the relaxation frequency, $W$ the activation energy associated with the relaxation process, $K$ the Boltzmann constant and $T_{\mathrm{m}}$ the transition temperature.

The results of the experimental investigation carried out at high ultrasonic frequencies show that the attenuation of ultrasonic waves in composites depends on the temperature and that only at those points where the mode of molecular motion is changed does the temperature coefficient of ultrasonic attenuation change discontinuously. Thus, the change of the molecular motion of the composite can be judged from the change in the temperature dependence on attenuation $\alpha=f(T)$. This corresponds to the condition under which a given type of molecular motion begins to start the relaxation process. The dependence of the transition temperature on the frequency of the applied ultrasonic field is associated with the phenomenon of glass transition which is due to the relaxation nature of the transition from glassy state to rubbery state. Moreover, this phase transition is of the second order where the internal energy and specific volume change smoothly while the heat capacity $(\partial v / \partial T)_{V}$ and compressibility $(\partial v / \partial \rho)_{T}$ change jump wise (Andrews and Hammack 1965). It is, therefore, suggested that this transition or relaxation, near these temperatures, is associated with thermally activated or reorientation of a given type of segmental or molecular motion.

The results show that the transition observed at ultrasonic frequencies involves the same relaxation processes as the glass transition. The glass temperatures of polyester was found to be $268^{\circ} \mathrm{K}$, whereas it increases with the increase of fibre glass to reach $353^{\circ} \mathrm{K}$ for $60 \mathrm{wt} \%$ fibre glass. The reported increase in activation energy values with increasing fibre glass content is in agreement with the results reported for elastic moduli.

\section{Conclusion}

Results show that increase in activation energy values with increasing fibre glass fraction is in agreement with results reported for elastic moduli. Good agreement was found between the longitudinal elastic moduli determined ultrasonically and those measured mechanically. 


\section{Acknowledgement}

The author thanks Miss E H H Younis, Testing of Material Department, National Institute for Standards, for the help she offered throughout this study.

\section{References}

Andrews R D and Hammack T 1965 J. Polym. Sci. B3 659

Chang D C and Weng G J 1979 J. Mater. Sci. 142183

Gupta V B, Mittal R K and Malti Goel 1990 Composites Sci. \& Technol. 37353

Hull D 1981 An introduction to composite materials (London: Cambridge University Press)

Kinra V K, Ker E and Datta S K 1982 Mech. Res. Commun. 9109

Klinman R, Webster G R, March F J and Stephenson E T 1980 Materials Evaluation p. 26

Madhava M R, Raman S, Pavitran C, Prasad S V and Rohatgi P K 1983 J. Pure Appl. Ultrason. 539

Mongy M, Abd El-Malak N A and El-Sabeé M 1982 Acoustica 51187

Nguyen N T, Lethiecq M and Gerard J F 1995 Ultrasonics 33323

Reger M, Seeleuthner P and Baptiste D 1992 European conf. on composite testing and standardization (Amsterdam: ECCM-CTS) p. 297

Sato N, Kurauchi T, Sato S and Kamigaito O 1988 J. Comp. Mater. 22850

Sayers C M and Smith R L 1982 Ultrasonics 20201

Smith R L and Reynolds W N 1982 J. Mater. Sci. 171420

Truell R, Elbaum C and Chick B B 1969 Ultrasonic methods in solid state physics (New York: Academic Press) Vary A 1980 Research techniques in nondestructive testing (ed.) R S Sarpe (London: Academic Press) Vol. IV Ying C F and Truell R 1956 J. Appl. Phys. 271086

Younis E H 1995 Studies on the environmental fatigue behaviour and the characterization of reinforced polyester composites, $\mathrm{M} \mathrm{Sc}$ Thesis, Cairo University, Cairo 